\title{
Common Arterial Trunk from Third Part of Axillary Artery
}

\author{
Darshna Gulabrao Fulmali¹, Preeti Prabhakarrao Thute ${ }^{2}$, Harsha Atul Keche ${ }^{3}$, Vilas Keshavrao Chimurkar ${ }^{4}$
}

1,2,3,4 Department of Anatomy, Jawaharlal Nehru Medical College, Sawangi (Meghe), Wardha, Maharashtra, India.

\section{PRESENTATION OF CASE}

During usual dissection of the upper extremity for the first year MBBS students in the Department of Anatomy, we observed unilateral variant branching pattern of third part of axillary artery on the right side in a middle aged male cadaver. Course and branching pattern of first, second and third part of axillary artery on the left side was found to be normal. On the right side also, course and branches of axillary artery were found to be normal in its first and second part but axillary artery in its third part divided in to two equal calibre arterial trunks lateral and medial. Lateral common arterial trunk courses laterally for a distance of $1 \mathrm{~cm}$ and then passes through two roots of median nerve. Further in its course it gives three branches, anterior circumflex humeral from anterolateral aspect, posterior circumflex humeral from posterolateral surfaces and subscapular artery from anteromedial surfaces and the trunk continues as profunda brachii artery which runs along with radial nerve through radial groove. Superior and inferior ulnar collateral artery arose from the profunda brachii artery instead of brachial artery, while medial trunk courses downwards medial to median nerve in arm. It continues as brachial artery at the lower border of teres major muscle and doesn't give any branch in its further course in arm. The trunk divides in to two terminal branches, radial and ulnar artery at the radial tuberosity.

Subclavian artery courses from the external border of clavicle to the lower edge of teres major muscle as axillary artery. It is partitioned by the covering of pectoralis major muscle into three sections. It offers six branches, one from the initial segment, two from the subsequent part and three branches from the third part of the artery. Superior thoracic emerges from initial segment, thoraco-acromial and long thoracic artery conduit from the subsequent part and anterior circumflex humeral, posterior circumflex humeral and subscapular artery from the third part of axillary. Two roots of median nerve embrace the third part of axillary artery and join with each other to form the trunk of nerve which is usually related to the lateral aspect of the axillary artery. ${ }^{1}$ Nerves as well as vessels during their course to the area of concern, may contravene the usual course and exhibited as variant distribution. Variation in the course of neurovascular bundle, the main content of the axilla, has been documented by many researchers. This is a unique instance of variation of third part of axillary artery.
Corresponding Author: Dr. Darshna Gulabrao Fulmali, Department of Anatomy, Aaditya Residency,

Sarthak, Banglow No. 2, Sawangi Meghe Wardha, Maharashtra, India.

E-mail: bhotmagey2010@gmail.com

DOI: $10.14260 /$ jemds/2020/765

How to Cite This Article:

Fulmali DG, Thute PP, Keche HA, et al. Common arterial trunk from third part of axillary artery. J Evolution Med Dent Sci 2020;9(46):3497-3499,

$10.14260 / \mathrm{jemds} / 2020 / 765$

Submission 01-08-2020,

Peer Review 02-10-2020,

Acceptance 19-10-2020,

Published 16-11-2020.

Copyright (C) 2020 Darshna Gulabrao Fulmali et al. This is an open access article distributed under Creative Commons Attribution License [Attribution 4.0 International (CC BY 4.0)] 


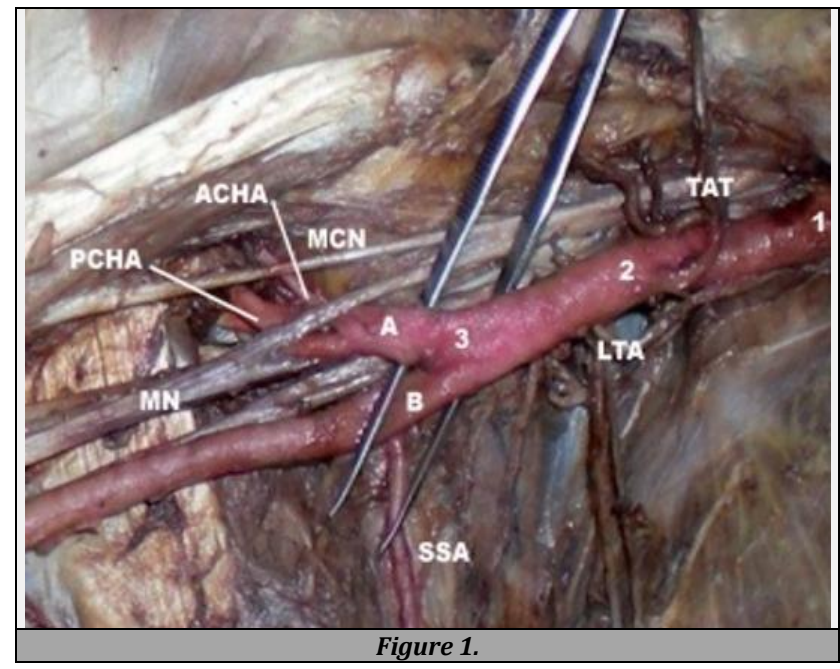

Showing division of third part of axillary artery into two equal calibre arterial trunk $A$ and trunk $B$ passing between two roots of median nerve LTA-Lateral Thoracic Artery, ACHAAnterior Circumflex Humeral, PCHA-Posterior Circumflex Humeral, SSA-Subscapular, PBA-Profunda Brachii Artery, MNMedian Nerve (Figure 1)

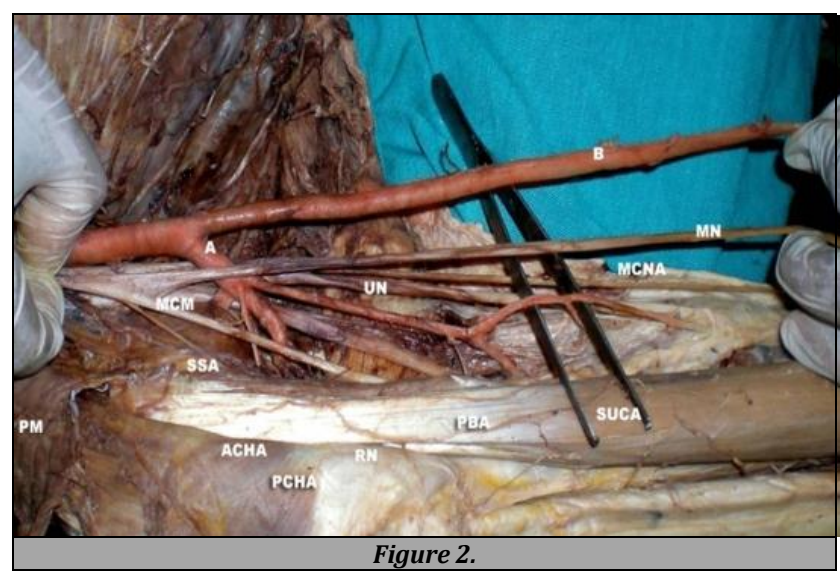

Showing branches from common arterial trunk B giving origin to ACHA, PCHA, SSA, PBA and PBA artery giving origin to ulnar collateral artery, LTA, ACHA, PCHA, SSA, PBA, MN, SUCA-Superior Ulnar Collateral Artery, UN-Ulnar Nerve (Figure 2)

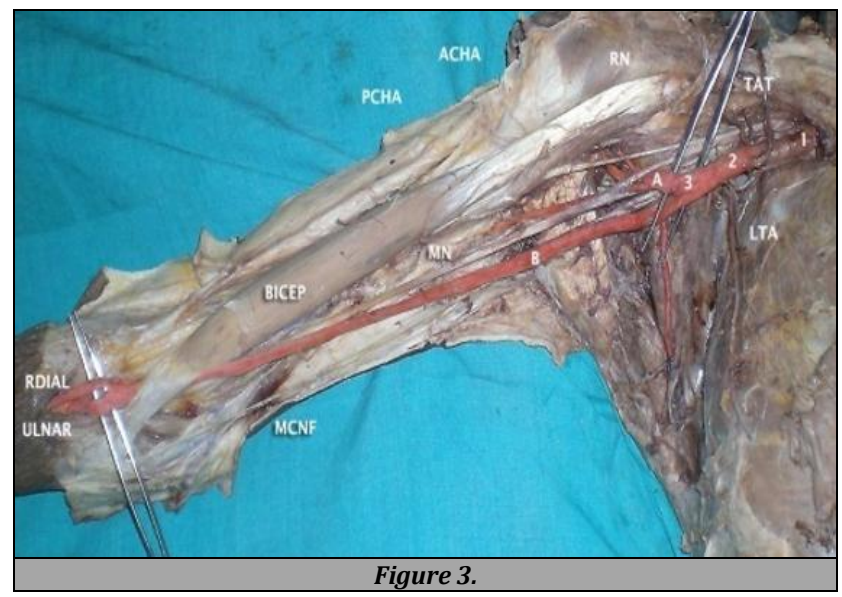

Showing continuation of Trunk-A in arm and its further division in to radial and ulnar artery LTA, ACHA, PCHA, SSA,
PBA, MN, SUCA, UN, MCNA-Medial Cutaneous Nerve of arm (Figure 3).

\section{DISCUSSION}

Varieties in the branches emerging from axillary artery have been recorded by many authors. De Garis and Swartley (1928) reported five to eleven branches emerging from the axillary artery however the commonest number in reading material of anatomy are six branches, one branch from initial segment, two from second part, and three from third part of axillary artery. $^{2}$ Branches from the axillary artery emerged independently or as a common arterial trunk from any of the three part of axillary artery. ${ }^{3}$ Variant common arterial trunk arising from axillary artery was documented by many authors. Common arterial trunk arising from first part of axillary artery giving origin to branches that normally originate from second and third part of axillary artery were observed by $\mathrm{E} M$ Goldman (2012) and Deepak Patil (2016).4,5 Common arterial trunk arising from second part and dividing into branches that normally arises from the second or third part were documented by Saeed M (2002) T Srimathi (2011) Ranjana Verma (2014) Javed Akhatar (2016). ${ }^{6,7,8,9}$

\begin{tabular}{|c|c|c|c|}
\hline Authors & Year & $\begin{array}{c}\text { Part of the Axillary } \\
\text { Giving Origin to } \\
\text { Common Arterial } \\
\text { Trunk }\end{array}$ & $\begin{array}{c}\text { Branches from Common } \\
\text { Arterial Trunk }\end{array}$ \\
\hline E M Goldman et al. & 2012 & \multirow[t]{3}{*}{ First part } & $\begin{array}{l}\text { TAA, SSA giving Origin to } \\
\text { PCHA, LTA }\end{array}$ \\
\hline Deepak Patil et al. & 2016 & & ACTH, PCHA, SSA, PBA \\
\hline Saeed M et al. & 2002 & & $\begin{array}{c}\text { LTA, CHA, SSA, TDA } \\
\text { Thoracohumeral Trunk (1.9 } \\
\%)\end{array}$ \\
\hline T Srimathi et al. & 2011 & \multirow{3}{*}{ Second part } & TAA,LTA,SSA,PCHA \\
\hline RanjanaVerma et al. & 2014 & & TAA, SCA, Collateral Branch \\
\hline Javed Akhatar et al. & 2016 & & LTA,SSA \\
\hline Saeed M et al. & 2002 & \multirow{4}{*}{ Third part } & $\begin{array}{c}\text { ACHA, PCHA, TDA } \\
\text { Subscapular-Circumflex } \\
\text { Humeral Trunk }(3.8 \%)\end{array}$ \\
\hline Divya Agrawal et al. & 2012 & & $\begin{array}{l}\text { LTA, SSA, PCHA, CSA, } \\
\text { Muscular branch }\end{array}$ \\
\hline $\begin{array}{l}\text { Ishwar B. Bagoji et } \\
\text { al. }\end{array}$ & 2013 & & $\begin{array}{c}\text { CSA, LTA, TDA, PCHA } \\
\text { Subscapular Trunk Roots of } \\
\text { Median Nerve are Related to } \\
\text { deep Brachial Artery }\end{array}$ \\
\hline Aritra Banerjee et al. & 2017 & & PCHA,LTA \\
\hline D Venieratos et al. & 2001 & \multirow{5}{*}{ Third part } & ACTH, PCHA, PBA, UCA \\
\hline Samual VP et al. & 2006 & & $\begin{array}{c}\text { ACTH, PCHA, SSA, RCA, MCA, } \\
\text { SUCA }\end{array}$ \\
\hline Kumar Naveen et al. & 2014 & & $\begin{array}{c}\text { ACTH, PCHA, SSA, PBA as } \\
\text { Continuation } \\
\text { CT pass between two Roots of } \\
\text { Median Nerve }\end{array}$ \\
\hline Aastha et al. & 2015 & & $\begin{array}{c}\text { ACTH, PCHA, SSA, PBA } \\
\text { Ulnar and Radial Collateral } \\
\text { from PBA }\end{array}$ \\
\hline Our Findings & 2020 & & $\begin{array}{c}\text { ACTH, PCHA, SSA, PBA SUCA, } \\
\text { IUCA from PBA }\end{array}$ \\
\hline
\end{tabular}

Showing common arterial trunks with various branches arising from the first, second, third part of the axillary artery as reported by different authors CT-Common Trunk, TAAThoracoacromial Artery, LTA, CSA-Circumflex Scapular Artery, TDA-Thoracodorsal Artery, ACTH- Anterior Circumflex Humeral, PCH-Posterior Circumflex Humeral, SSA, PBA, RCARadial Collateral, MCA-Middle Collateral, UCA-Ulnar Collateral Artery, SUCA-Superior Ulnar Collateral Artery, IUCA-Inferior Ulnar Collateral Artery (Table 1).

We detailed a common arterial trunk emerging from the third part which divides into three branches that normally are the branches of third part individually and continues as 
profunda brachi artery. The profunda brachii artery in this case gave origin to collateral branches instead of brachial artery. Saeed M (2002) found common arterial trunk branching into ACHA, PCHA, TDA. ${ }^{6}$ Divya Agrawal (2012) found it branching into LTA, SSA, PCHA, CSA, ${ }^{10}$ Ishwar B. 2013 into CSA, LTA, TDA, PCHA ${ }^{11}$ and Aritra Banerjee (2017) into PCHA, LTA. Samuel VP also documented a common arterial trunk, which gives origin to branches arising normally from the third part and in addition it gives origin to radial collateral, middle collateral and superior ulnar collateral arteries but with absence of profunda brachii artery ${ }^{12}$. SAEED case this common trunk gives rise to subscapular artery, anterior and posterior circumflex humeral artery in addition to the lateral thoracic thoraco-acromial artery, ${ }^{6}$ but the course of profunda brachi was normal in that case. Samual VP (2006) also reported a common trunk but unlike us observed RCA, MCA, SUCA arising from profundabrachi. ${ }^{13}$ Kumar Naveen (2014) Aastha also documented a common arterial trunk continuing as profunda brachi artery which gives ulnar collateral but unlike us it also gives radial collateral artery from the profunda brachi. ${ }^{14,15}$

Degaris \& Swartley and Huelke reported on the basis of large scale study on the branching pattern of axillary artery that the subscapular; both circumflex humeral and profunda brachii arteries arose frequently from the axillary artery as a common trunk in combination of any of two or more. ${ }^{2}$ According to Eumet al, 1991 the profunda brachii artery arose occasionally from the axillary artery by a common trunk with the subscapular and both circumflex humeral arteries. ${ }^{16}$ Jonson stated that subscapular artery arises from common arterial trunk with posterior circumflex humeral artery in 30 $\%$ of cases. In some cases subscapular, circumflex humeral and profunda brachii arteries arise in common and was surrounded by branches of the brachial plexus. ${ }^{17}$ Regression, retention or reappearance of any vessels during embryonic development of vascular plexus of the upper limb result into formation of vas aberrans. ${ }^{18}$

Surgeons should be aware of the normal as well as the variant branching pattern of axillary artery to prevent accidental vascular injury during surgical intervention in the axillary region to avoid complication. In this case the common arterial trunk passes between two roots of median nerve and may get compressed between the roots leading to inadequate blood supply to the arm. Knowledge about the variation is also essential for orthopaedician during correction of shoulder dislocation. ${ }^{19}$ As the branches of axillary artery are used as graft of coronary bypass, vascular surgeons should be aware about the variant axillary artery branching pattern.

Financial or other competing interests: None.

Disclosure forms provided by the authors are available with the full text of this article at jemds.com.

\section{REFERENCES}

[1] Standring S. Grey's anatomy. 40 th edn. Churchill Livingstone 1989:814-9.

[2] De Garis CF, Swartley WB. The axillary artery in white and Negro stocks. Am J Anat 1928;41(2):353-97.

[3] Holinshed WH. Anatomy for surgeons in general surgery of the upper limb. The back and limbs. New York: A Heber Harper Book 1958:290-300.

[4] Goldman EM, Shah YS, Gravante N. A case of an extremely rare unilateral subscapular trunk and axillary artery variation in a male Caucasian: comparison to the prevalence within other populations. Morphologie 2012;96(313):23-8.

[5] Patil DA, Jadhav AS, Katti AS. Anatomical study of axillary artery variations. Int J Anat Res 2016;4(4):3117-21.

[6] Saeed M, Rufai AA, Elsayed SE, et al. Variation in subclavian - axillary arteril system. Saudi Med J 2002;23(2):206-12.

[7] Srimathi T. Abnormal branching pattern of the axillary artery-a case report. Int J Basic Med Sci 2011;2(4):73-6.

[8] Verma R, Mishra S, Mahajan A. Unilateral variation in the branching pattern of axillary artery: a cadaveric study. Int J Anat Res 2014;2(1):292-94.

[9] Akhtar MD, Rahman S, Kumar B, et al. A rare variation in the branching pattern of axillary artery. Saudi J Health Sci 2016;5(1):39-41.

[10] Agrawal D, Singh N, Mohanty BB, et al. Variation in the branching pattern of axillary artery-a case report. Int J Anat Var 2013;6:31-3.

[11] Bagoji IB, Hadimani GA, Patil BS, et al. Anomalous sub scapulo-suprascapular arterial trunk-a case report. IOSR J Dent Med Sci 2012;1(1):5-6.

[12] Banerjee AA, Kumari CA, Jhajhria SJ. Variation in the branching pattern of third part of axillary artery- a case report. J Clin Diagn Res 2017;11(2):AD03-4.

[13] Samuel V, Vollala V, Nayak S, et al. A rare variation in the branching pattern of the axillary artery. Indian J Plast Surg 2006;39(2):222-3.

[14] Naveen K, Jyothsna P, Nayak SB, et al. Variant origin of an arterial trunk from axillary artery continuing as profunda brachii artery -- a unique arterial variation in the axilla and its clinical implications. Ethiop J Health Sci 2014;24(1):93-6.

[15] Aastha, Jain A, Kumar MS. An unusual variation of axillary artery: a case report. J Clin Diagn Res 2015;9(1):AD05-7.

[16] Huelke DF. Variation in the origins of the branches of the axillary artery. Anat Rec 1959;135(1):33-41.

[17] Johnson D, Ellis H. Pectoral girdle and upper limb. In: Standring S, eds. Gray's anatomy. 39th edn. Edinburgh: Elsevier 2005: p. 845.

[18] Hamilton WJ, Mossman HW. Cardiovascular system. In: Human embryology. $4^{\text {th }}$ edn. Baltimore: Williams and Wilkins 1972:271-90.

[19] Williams PL, Bannister LK, Berry MM, et al. Gray's Anatomy. In: Gabella G, ed. Cardiovascular system. 38 edn. Edinburgh: Churchill Livingstone 1995:1537-8. 